\title{
Allelopathic Effects of Different Organs of Redroot Pigweed (Amaranthus retroflexus L.) on Cucumber and Wheat Plants
}

\author{
Hamideh Bakhshayeshan-Agdam ${ }^{1}$, Seyed Yahya Salehi-Lisar ${ }^{1}$, Rouhollah Motafakkerazad ${ }^{1}$, Amirhosein \\ Talebpour $^{2}$ and Nader Farsad ${ }^{1}$ \\ 1. Department of Plant Sciences, Faculty of Natural Sciences, University of Tabriz, Tabriz 5166616471, Iran \\ 2. Agricultural and Natural Resources Research Center of East Azerbaijan, Tabriz 5716964455, Iran
}

\begin{abstract}
Allelopathy is one of the most important interactions between plants. Weeds are famous plants from this viewpoint, which can decrease crop production in farms by their allelopathic effects. Research has shown that different plant organs have different allelopathic effects. Redroot pigweed (Amaranthus retroflexus L.) is one of the most common weeds with well-known allelopathic potential. This experiment aimed to study the allelopathic effects of different organs' leachate of redroot pigweed on germination and growth of cucumber (Cucumis sativus L.) and wheat (Triticum aestivum L.) as two important crop species. The effect of different organs' leachate on seed germination and seedlings growth parameters of tested plants was significantly different. In addition, the effects on cucumber were not the same as wheat. According to the results, wheat plant was more resistant at both seed germination and seedling growth stages in comparison to cucumber. Cucumber only showed normal growth potential when treated with the stem leachate, while wheat showed measurable growth potential in all treatments and leaf leachate showed the highest negative effect on wheat. Accordingly, allelopathic effects of redroot pigweed are dependent not only on leachate concentration and plant species, but also on plant organ from which the leachate was released. Therefore, understanding the allelochemical source (organ) of a donor plant is essential for accurate evaluation of allelopathic interactions between plants.
\end{abstract}

Key words: Allelopathy, redroot pigweed, resistance, crop, different organs’ leachate.

\section{Introduction}

One of the famous and effective flora components in agricultural lands is weeds and they are important plant groups in the allelopathic interactions as well. Basic information of allelopathic phenomenon was obtained by studying various weed plants $[1,2]$. In allelopathic interactions, plants fight together by producing and releasing secondary compounds [3-5]. Certain secondary compounds that involved in allellopathic interactions are called allelochemicals [3, $5,6]$. Plants producing allelochemicals and affected by these compounds are named donor and receiver plants, respectively [7]. Usually, researchers focused on weeds as donor plants $[2,6,7]$. Plants can release

Corresponding author: Seyed Yahya Salehi-Lisar, associated professor, research field: plant physiology. these phytotoxic compounds into the environment by different ways, such as leaching from the shoot by rainfall, releasing volatile compounds from plant's green parts, leaching after decomposition of plant material and eventually releasing by the root exudates $[3,6,8,9]$. Redroot pigweed (Amaranthus retroflexus L.) is one of the most famous weeds with the well-known allelopathic effects on other plants [1, 10-12]. Many studies have been conducted on redroot pigweed's allelopathic effects on different crops, such as barley [10], wheat [11, 13], cucumber [13], garden cress [14], maize [12,15] and common bean [16] by other researchers. Several allelic compounds, such as aldehydes, alkaloids, apocarotenoids, flavonoids, steroids, xyloids, chlorogenic acid and saponins from amaranth residues have been reported $[10,11]$. 
Redroot pigweed is one of the few resistant plants to several herbicides, including atrazine, simazine, imazethapyr, thifensulfuron and linuron [1, 17]. Different organs of plants could produce different allelochemicals [11, 18, 19]. Therefore, each organs of donor plant can cause different allelopathic effects on the same receiver plant. Accordingly, the present study was carried out in order to evaluate the allelopathic effects of different organs' leachate of redroot pigweed on germination and growth parameters of cucumber and wheat, which are sensitive and resistant species to allelopathic effects of redroot pigweed, respectively [13], and determine the most effective amaranth organ involved in its allelopathic interactions by other plants.

\section{Materials and Methods}

\subsection{Experimental Design and Treatments}

The experiment was conducted as factorial based on completely randomized design (CRD) with three replications. Experimental factors were crop species, including cucumber (Cucumis sativus L. "Basmenj") and wheat (Triticum aestivum L. "Phishgam"), and redroot pigweed leachate from different organs, including root, stem, leaf and flower. Sterile double distilled water was considered as control.

\subsection{Sampling and Plant Extract Preparation}

Fresh material of redroot pigweed's whole plant, including flower, leaf, stem and root, was collected from crop fields of Khosroshahr (East Azerbaijan, Iran) and powdered after air drying under lab conditions. For leachate preparation, $10 \mathrm{~g}$ of powdered material of each organ were separately suspended in $200 \mathrm{~mL}$ of sterile double distilled water and mixed for $24 \mathrm{~h}$ by a horizontal rotary shaker for producing uniform suspension $[10,11,14]$. Suspension was filtered using two layers of sterile cheesecloth and filtrate was considered as $5 \%$ leachate.

\subsection{Plant Culture and Bioassay Tests}

The seeds of wheat (Triticum aestivum L. "Phishgam") and cucumber (Cucumis sativus L. "Basmenj”) were supplied by Agricultural and Natural Resources Research Center of East Azerbaijan (Tabriz, Iran). Appropriate numbers of seeds were selected based on their vigour and uniformity, disinfected using $1 \%(\mathrm{v} / \mathrm{v})$ sodium-hypochlorite solution for $5 \mathrm{~min}$ and sufficiently washed using sterile distilled water. Ten seeds of each species were placed in each Petri dish containing sterile filter paper, and $5 \mathrm{~mL}$ of organs leachate $5 \%$ was added. Control seeds were moistened with $5 \mathrm{~mL}$ of sterile double distilled water. Petri dishes were sealed with parafilm for prevention of pollution and water evaporation, and then transferred to darkness. After $2 \mathrm{~d}$, all germinated seeds were transferred to growth chambers with controlled conditions $\left(25-30{ }^{\circ} \mathrm{C}, 16 \mathrm{~h} / 8 \mathrm{~h}\right.$ light/dark photoperiod and relative humidity of $60 \%$ ). The percentage of germinated seeds was recorded daily, and growth parameters like seedling length, shoot length, seminal root length, fresh and dry weight of seedlings were determined after $7 \mathrm{~d}$. Relative growth rate (RGR) [20] and seedling survival rate (SSR) [21] were calculated using following Eqs. (1) and (2), respectively:

$$
\mathrm{RGR}=\frac{\Delta y}{y \Delta t} \times 100
$$

where, $\Delta y$ is the growth amount, $\Delta t$ is the growth time (day) and $y$ is the fresh/dry weight of primary tissue or organ.

$$
\mathrm{SSR}=\frac{\mathrm{A}}{\mathrm{B}} \times 100
$$

where, $\mathrm{A}$ is the number of seedlings and $\mathrm{B}$ is the number of germinated seeds.

\subsection{Data Analysis}

The data were analyzed using general linear model (GLM) procedure by SPSS software (version 16) and Tukey's multiple range tests were used for mean comparison at $1 \%$ probability level. 


\section{Results}

According to statistical evaluation (analysis of variance), the effect of different organs of redroot pigweed's leachate on seed germination percentage, seedling shoot and seminal root length, fresh and dry weight of seedlings and its interaction with crop species was significant $(P<0.01)$. However, the effect of different organs' leachate on seed germination and seedlings growth of studied species was not the same (Table 1).

\subsection{Seed Germination}

Different organs' leachate of redroot pigweed showed different effects on the seed germination percentage of cucumber and wheat plants. Germination percentage of cucumber declined significantly in all tested treatments. Flower and stem leachates caused the highest and lowest reduction in germination of cucumber seeds, respectively. A decline in wheat seeds germination in all treatments was observed, but compared to controls, differences were not significant $(P<0.01)$. However, the effect of all organs' leachate was significant at $P<0.05$ (Fig. 1). Daily recording of germination percentage indicated a delay phase in germination of both species in all treatments and the length of delay phase was dependent on the type of leachate and plant species (Fig. 2). On the other hand, root leachate caused the lowest delay time in wheat plants, whereas the highest delay time was observed in cucumber seeds treated by flower leachate.

\subsection{Seedling Survival Rate}

The effect of different organs' leachate on seedling survival rate in wheat and cucumber was quite different. Seedling survival rate of cucumber treated by flower, leaf and root leachate was zero, whereas the leachate of stem had no significant effect on

Table 1 Mean squares of redroot pigweed leachate concentration' effect on germination and growth related characteristics of crop species.

\begin{tabular}{|c|c|c|c|c|c|c|c|c|c|}
\hline Source of variation & Df & $\begin{array}{l}\text { Shoot length } \\
(\mathrm{mm})\end{array}$ & $\begin{array}{l}\text { Seminal root } \\
\text { length }(\mathrm{mm})\end{array}$ & $\begin{array}{l}\text { Seedling } \\
\text { length }(\mathrm{mm})\end{array}$ & $\begin{array}{l}\text { Fresh weight } \\
(\mathrm{mg})\end{array}$ & $\begin{array}{l}\text { Dry weight } \\
(\mathrm{mg})\end{array}$ & $\begin{array}{l}\text { Germination } \\
\text { percentage } \\
(\%)\end{array}$ & SSR (\%) & $\begin{array}{l}\text { RGR } \\
\text { (\%, per } \\
\text { day) }\end{array}$ \\
\hline Treatments & 4 & $3,433.61^{* *}$ & $21,839.74^{* *}$ & $41,674.13^{* *}$ & $43,423.92^{* *}$ & $337.37^{* *}$ & $2,696.67^{* *}$ & $4,653.34^{* *}$ & $33.67^{* *}$ \\
\hline Species & 1 & $1,1843.71^{* *}$ & $163.94^{\mathrm{ns}}$ & $14,794.52^{* *}$ & $1,971.70^{\mathrm{ns}}$ & $2,330.07^{* *}$ & $963.33^{\mathrm{ns}}$ & $20,202.07^{* *}$ & $315.71^{* *}$ \\
\hline Treatments $\times$ species & 4 & $887.15^{* *}$ & $191.38^{\mathrm{ns}}$ & $1,889.09^{* *}$ & $38,083.16^{* *}$ & $411.23^{* *}$ & $613.33^{\mathrm{ns}}$ & $1,881.32^{* *}$ & $41.82^{* *}$ \\
\hline Error & 20 & 56.49 & 80.13 & 232.87 & 877.17 & 20.70 & 266.67 & 207.44 & 2.16 \\
\hline CV $(\%)$ & & 25.05 & 29.83 & 50.87 & 98.72 & 15.16 & 54.43 & 48.01 & 4.90 \\
\hline
\end{tabular}

${ }^{* *}$ Significant at $P<0.01$ by Tukey's multiple range tests $(n=3)$; ns: not significant.

$\mathrm{CV}$ : coefficient of variation; Df: degree of freedom; RGR: relative growth rate; SSR: seedling survival rate.

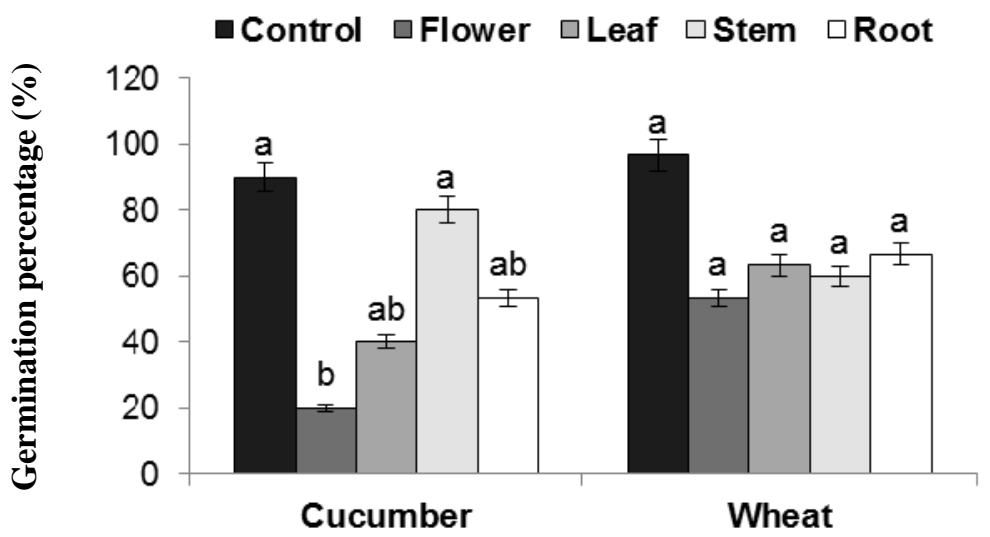

Fig. 1 The effect of different organs' leachate of the redroot pigweed on seed germination of wheat and cucumber.

The data represent the mean of three replications and different letters in each species show significantly different values at $P<0.01$. 


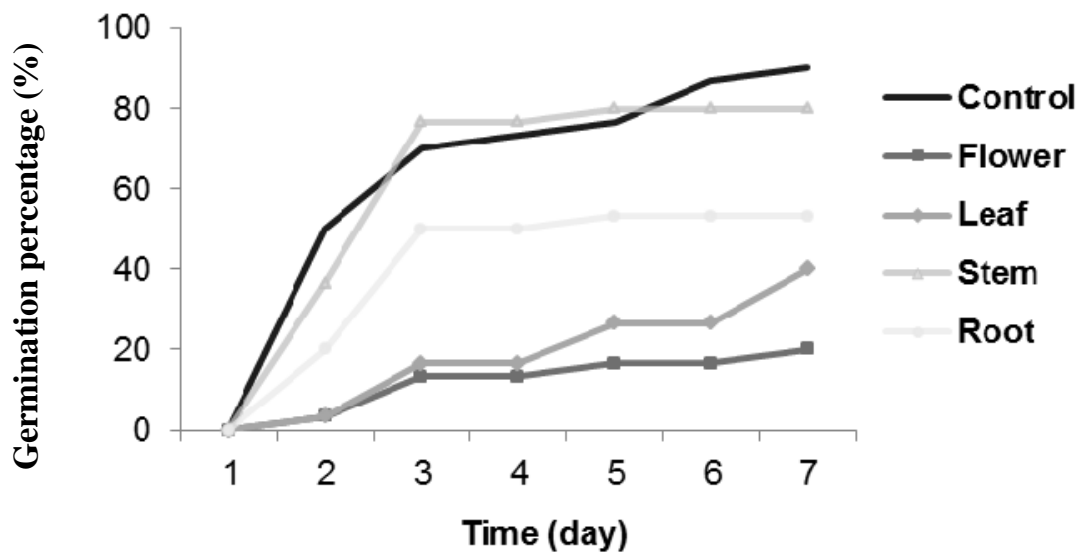

(a) Cucumber

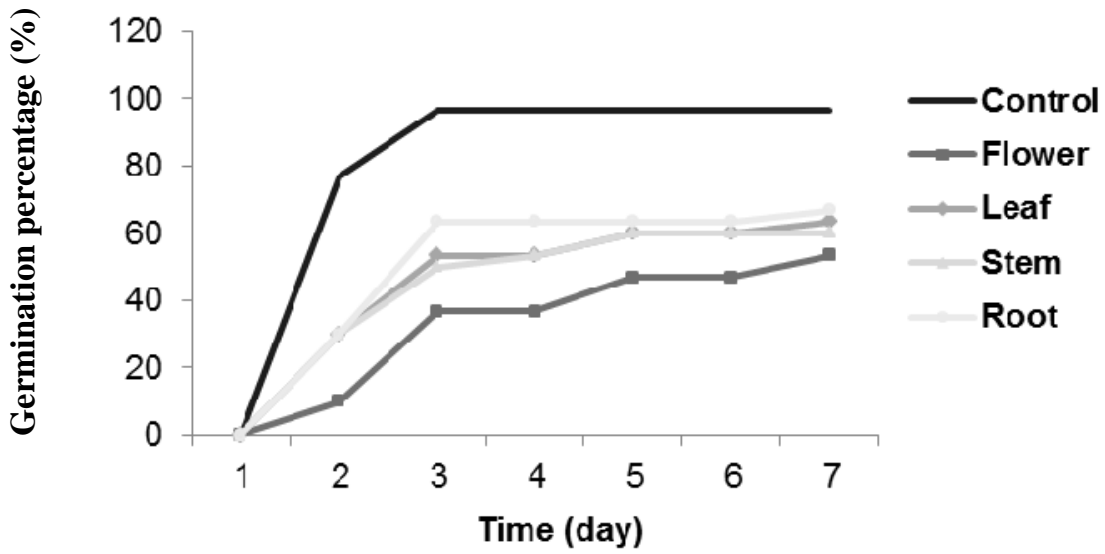

(b) Wheat

Fig. 2 Effects of redroot pigweed different organs' leachate on seed germination of cucumber (a) and wheat (b) during $7 \mathrm{~d}$ after treatment.

The data represent the mean of three replications and different letters in each species show significantly different values at $P<0.01$.

seedling survival rate $(P<0.01)$. In wheat plants, similar to germination percentage, reduction in seedling survival rate was observed in all treatments, but the trend was not significant $(P<0.01)$. However, the effect of all organs leachate was significant at $P<$ 0.05 (Fig. 3).

\subsection{Shoot, Seminal Root and Seedling Length}

Shoot length of both species were significantly affected by different organs leachate of redroot pigweed $(P<0.01)$. Effects were severe in cucumber plants and shoot length decreased by $100 \%$ in flower, leaf and root leachate treatments, but in wheat plants the highest reduction in shoot length was $43.8 \%$ in seedlings treated by leaf leachate in comparison with the control (Table 2).

In both studied species, seminal root length was significantly decreased in plants treated with all organs' leachate of redroot pigweed in comparison with the control, but the differences between plants treated with leachate of different organs were not significant $(P<0.01)$. Similar to shoot length, effects on seminal root length in cucumber plants were higher and decreased by $100 \%$ in flower, leaf and root leachate treatments; but in wheat, the highest decrease in this parameter was $94.48 \%$ in plants treated by leaf leachate in comparison with the control (Table 2).

The results of seedling length were similar to the results of shoot and seminal root length. In cucumber plants, stem leachate of redroot pigweed caused the 


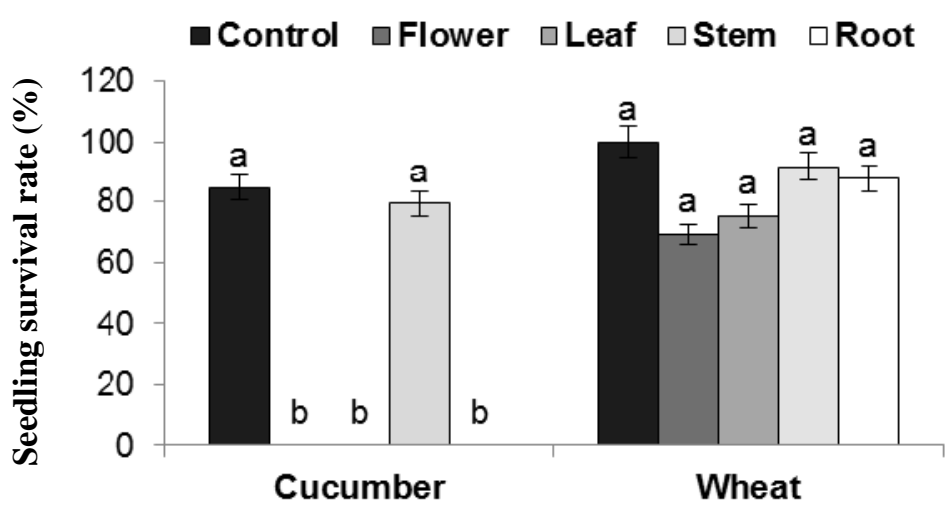

Fig. 3 The effects of different organs' leachate of the redroot pigweed on seedling survival rate of crop species.

The data represent the mean of three replications and different letters in each species show significantly different values at $P<0.01$.

Table 2 The effect of different organs leachate of the redroot pigweed on shoot, seminal root and seedling length (mm) and shoot/seminal root length ratio of crop species $(n=3, P<0.01)$.

\begin{tabular}{llllll}
\hline \multirow{2}{*}{ Plant species } & \multirow{2}{*}{ Organs } & \multicolumn{4}{c}{ Parameters } \\
\cline { 3 - 6 } & Control & $75.13 \pm 8.64^{\mathrm{a}}$ & $145.23 \pm 23.92^{\mathrm{a}}$ & $220.37 \pm 31.88^{\mathrm{a}}$ & $0.52 \pm 0.05^{\mathrm{b}}$ \\
\hline \multirow{3}{*}{ Cucumber } & Shoot length & $0.00 \pm 0.00^{\mathrm{c}}$ & $0.00 \pm 0.00^{\mathrm{b}}$ & $0.00 \pm 0.00^{\mathrm{c}}$ & $0.00 \pm 0.00^{\mathrm{c}}$ \\
& Leaf & $0.00 \pm 0.00^{\mathrm{c}}$ & $0.00 \pm 0.00^{\mathrm{b}}$ & $0.00 \pm 0.00^{\mathrm{c}}$ & $0.00 \pm 0.00^{\mathrm{c}}$ \\
& Stem & $44.55 \pm 11.84^{\mathrm{b}}$ & $22.18 \pm 7.90^{\mathrm{b}}$ & $66.73 \pm 19.71^{\mathrm{b}}$ & $2.05 \pm 0.19^{\mathrm{a}}$ \\
& Root & $0.00 \pm 0.00^{\mathrm{c}}$ & $0.00 \pm 0.00^{\mathrm{b}}$ & $0.00 \pm 0.00^{\mathrm{c}}$ & $0.00 \pm 0.0^{\mathrm{c}}$ \\
\hline \multirow{3}{*}{ Wheat } & Control & $90.89 \pm 3.95^{\mathrm{a}}$ & $141.55 \pm 4.42^{\mathrm{a}}$ & $232.43 \pm 6.73^{\mathrm{a}}$ & $0.64 \pm 0.03^{\mathrm{b}}$ \\
& Flower & $62.82 \pm 12.96^{\mathrm{ab}}$ & $15.48 \pm 8.03^{\mathrm{b}}$ & $78.30 \pm 20.99^{\mathrm{b}}$ & $4.45 \pm 1.14^{\mathrm{a}}$ \\
& Leaf & $51.08 \pm 12.07^{\mathrm{b}}$ & $7.80 \pm 5.69^{\mathrm{b}}$ & $58.88 \pm 17.75^{\mathrm{b}}$ & $5.32 \pm 2.35^{\mathrm{a}}$ \\
& Stem & $55.89 \pm 4.05^{\mathrm{b}}$ & $11.85 \pm 4.70^{\mathrm{b}}$ & $67.74 \pm 8.75^{\mathrm{b}}$ & $5.07 \pm 1.36^{\mathrm{a}}$ \\
& Root & $57.70 \pm 2.17^{\mathrm{b}}$ & $14.10 \pm 5.28^{\mathrm{b}}$ & $71.81 \pm 6.79^{\mathrm{b}}$ & $4.61 \pm 2.10^{\mathrm{a}}$
\end{tabular}

Different letters in each column for each species show significantly different values at $P<0.01$.

lowest $(69.72 \%)$ decline in seedling length. In wheat plants, the lowest (66.31\%) and highest (74.67\%) decrease were observed in plants treated by flower and leaf leachate in comparison with the control, respectively (Table 2 ).

Leachate of redroot pigweed organs had different effects on shoot/seminal root length ratio of cucumber. Leachate of flower, leaf and root significantly decreased this ratio, but stem leachate significantly increased this parameter in comparison with the control $(P<0.01)$. The shoot/seminal root length ratio in wheat plants significantly increased in all tested treatments in comparison with the control $(P<0.01)$ (Table 2$)$.

\subsection{Fresh and Dry Weight of Seedlings}

Except stem leachate, all of the other organs leachate led to a significant decrease in seedling fresh weight of cucumber. Seedling fresh weight of wheat plants decreased in all tested treatments, but the trend was not significant $(P<0.01)$ (Table 3$)$.

The results of seedling dry weigh were similar to the results of seedling fresh weigh (Table 3 ). In cucumber, leachate of flowers, leaf and root decreased dry weight significantly $(P<0.01)$. The seedling dry weight in wheat plants increased in all tested treatments, but these differences were not significant in comparison with the control $(P<0.01)$.

\subsection{Relative Growth Rate}

The allelopathic effect of redroot pigweeds on relative growth rate was different depending on plant species and leachate source (Table 3 ). The results of 
Table 3 The effect of different organs leachate of redroot pigweed on fresh and dry weight of seedlings (mg) and relative growth rate (per day) of crop species $(n=3, P<0.01)$.

\begin{tabular}{lllll}
\hline \multirow{2}{*}{ Plant species } & Treatments & \multicolumn{3}{c}{ Parameters } \\
\cline { 3 - 4 } & Control & $307.64 \pm 33.01^{\mathrm{a}}$ & $22.92 \pm 5.05^{\mathrm{a}}$ & $7.26 \pm 1.60^{\mathrm{a}}$ \\
& Flower & $0.00 \pm 0.00^{\mathrm{b}}$ & $0.00 \pm 0.00^{\mathrm{b}}$ & $0.00 \pm 0.00^{\mathrm{b}}$ \\
\multirow{3}{*}{ Cucumber } & Leaf & $0.00 \pm 0.00^{\mathrm{b}}$ & $0.00 \pm 0.00^{\mathrm{b}}$ & $0.00 \pm 0.00^{\mathrm{b}}$ \\
& Stem & $293.31 \pm 86.41^{\mathrm{a}}$ & $32.69 \pm 11.84^{\mathrm{a}}$ & $10.36 \pm 3.75^{\mathrm{a}}$ \\
& Root & $0.00 \pm 0.00^{\mathrm{b}}$ & $0.00 \pm 0.00^{\mathrm{b}}$ & $0.00 \pm 0.00^{\mathrm{b}}$ \\
\hline \multirow{3}{*}{ Wheat } & Control & $113.59 \pm 5.03^{\mathrm{a}}$ & $24.81 \pm 0.32^{\mathrm{a}}$ & $8.64 \pm 0.11^{\mathrm{a}}$ \\
& Flower & $105.83 \pm 8.04^{\mathrm{a}}$ & $28.33 \pm 2.89^{\mathrm{a}}$ & $9.87 \pm 1.01^{\mathrm{a}}$ \\
& Leaf & $92.70 \pm 3.51^{\mathrm{a}}$ & $29.76 \pm 5.36^{\mathrm{a}}$ & $10.36 \pm 1.87^{\mathrm{a}}$ \\
& Stem & $106.03 \pm 9.52^{\mathrm{a}}$ & $30.00 \pm 1.43^{\mathrm{a}}$ & $10.45 \pm 0.50^{\mathrm{a}}$ \\
\hline
\end{tabular}

Different letters in each column for each species show significantly different values at $P<0.01$.

relative growth rate were similar to the results of seedling fresh and dry weigh.

\section{Discussion}

In the present study, redroot pigweed's different organs leachate caused $11.1 \%-77.8 \%$ reduction in seed germination of studied species. Allelopathic potential of redroot pigweed's organs has frequently been reported in Refs. [10-16]. According to the results of this research, cucumber is more sensitive to allelopathic effects of redroot pigweed than wheat in all treatments at both germination and seedling stages. Although cucumber is sensitive in both stages, apparently it has only little resistance in germination stage. Therefore, redroot pigweed's allelochemical compounds mostly affected cucumber plants after germination. It could be due to the fact that seeds of some plants, such as cucumber, have a protector layer which suppresses such allelopathic effects at the early phase. Results showed that stem leachate had the lowest effects on cucumber plants and fairly on wheat plants. In wheat plant, generally all treatments had similar effects and usually leaf leachate showed the highest effects. Allelochemical compounds produced in organs, tissues and sometimes even cells in a single donor plant can be different $[6,7,22,23]$. Studies have shown that allelochemicals in different parts of a donor plant are produced for different purposes [22,
23]. Allelochemicals type, concentrations and activities are also different depending on the organ, tissue or cell where they are produced (or depending on purpose of their production) [6, 7, 22, 23]. Capacity of organs for allelochemical accumulation differs from each other and depends on relative importance of that organ $[22,24]$. Some organs are suitable sink for some compounds in comparison to the other organs [24, 25]. Therefore, leachates extracted from different organs have different compounds, different concentration of each compounds and consequently different allelopathic effects. Allelopathic interactions always cause yield lose, therefore, understanding the allelochemical sources (organs) of a weed plant (especially donor plants) and their allelopathic effects is necessary for combat with weed plant, such as redroot pigweed. In addition to purposes followed in this study, conducting this experiment using soil, perlite or hydroponic culture of plants to obtain reliable results as well as identification of allelochemicals of each organ for quantitative and qualitative comparisons is suggested.

\section{Conclusions}

According to the results of this study, wheat was the most resistant species in all tested treatments and only leaf leachate showed considerable negative effect 
on it. Whereas, cucumber retained its growth potential only in plates treated with the stem leachate. Generally, redroot pigweed leachate of all organs affects cucumber more than wheat either on germination or growth parameters. Therefore, cultivation of wheat plant in the regions with redroot pigweed's invasion is affordable, and avoidance of cucumber cultivation in these regions is essential because this species is quite sensitive to compounds produce by different organs of redroot pigweed. Allelopathic effects of redroot pigweed depend on receiver plant species, as well as on plant organ from which leachate is extracted; however, amaranth allelopathic effects are mostly species-dependent. The most effective amaranth organ involved in its allelopathic interactions also depends on receiver plant species. While the most effective organs in wheat plants are flower and leaf, in cucumber, they are flower, leaf and root.

\section{References}

[1] Costea, M., Weaver, S., and Tardif, F. 2004. "The Biology of Canadian Weeds 130: Amaranthus retroflexus L., A. powellii S. Watson and A. hybridus L.." Canadian Journal of Plant Science 84 (2): 631-68.

[2] Dhole, J. A., Bodke, S. S., and Dhole, N. A. 2011. "Allelopathic Effect of Aqueous Extract of Five Selected Weed Species on Seed Mycoflora, Seed Germination and Seedling Growth of Sorghum vulgare Pers.." Research Journal of Pharmaceutical, Biological and Chemical Sciences 2 (3): 142-8.

[3] Amini, R. A., Movahedpour, F., Ghassemi-Golezani, K., Mohammadi-Nasab, A. D., and Zafarani-Moattar, P. 2012. "Allelopathic Assessment of Common Amaranth by ECAM." International Research Journal of Applied and Basic Sciences 3 (11): 2268-72.

[4] Khalaj, M. A., Amiri, M., and Azimi, M. H. 2013. "Allelopathy: Physiological and Sustainable Agriculture Important Aspects." International Journal of Agronomy and Plant Production 4: 950-62.

[5] Khan, A. L., Hussain, J., Hamayun, M., Kang, S. M., Kim, H. Y., Watanabe, K. N., and Lee, I. J. 2010. "Allelochemical, Eudesmane-Type Sesquiterpenoids from Inula falconeri." Molecules Journal 15 (3): 1554-61.

[6] Soltys, D., Krasuska, U., Bogatek, R., and Gniazdowska, A. 2013. "Allelochemicals as Bioherbicides: Present and
Perspectives." In Herbicides-Current Research and Case Studies in Use, edited by Price A. J., and Kelton, J. A. Rijeka, Croatica: InTech Publisher, 517-42.

[7] Sodaeizadeh, H., and Hosseini, Z. 2012. "Allelopathy: An Environmentally Friendly Method for Weed Control." In Proceedings of International Conference on Applied Life Sciences, 387-92.

[8] Terji, I. 2008. "Allelopathic Effects of Juglone and Decomposed Walnut Leaf Juice on Muskmelon and Cucumber Seed Germination and Seedling Growth." African Journal of Biotechnology 7 (12): 1870-4.

[9] Weir, T. L., Park, S. W., and Vivanco, J. M. 2004. "Biochemical and Physiological Mechanisms Mediated by Allelochemicals." Current Opinion in Plant Biology 7 (4): 472-9.

[10] Shahrokhi, S., Hejazi, S. N., Khodabandeh, H., Farboodi, M., and Faramarzi, A. 2011. "Allelopathic Effect of Aqueous Extracts of Pigweed, Amaranthus retroflexus L. Organs on Germination and Growth of Five Barley Cultivars." Proc. of Inter. Conf. on Chemical, Bio. and Environ. Eng. 20: 80-4.

[11] Shahrokhi, S., Darvishzadeh, M., Mehrpooyan, M., and Farboodi, M. 2012. "Comparison of Allelopathic Effects of Amaranthus retroflexus L. Different Organs Extracts on Germination and Initial Growth of Alvand and Zarrin Wheat Cultivars." International Journal of Agronomy and Plant Production 3: 489-94.

[12] Konstantinović, B., Blagojević, M., Konstantinović, B., and Samardžić, N. 2014. "Allelopathic Effect of Weed Species Amaranthus retroflexus L. on Maize Seed Germination." Romanian Agricultural Research 31: 1-7.

[13] Bakhshayeshan-Agdam, H., Salehi-Lisar, S. Y., Motafakkerazad, R., Talebpour, A. H., and Farsad, N. 2015. "Allelopathic Effects of Redroot Pigweed (Amaranthus retroflexus L.) on Germination and Growth of Cucumber, Alfalfa, Common Bean and Bread Wheat.” Acta Agriculturae Slovenica 2: 193-202.

[14] Mlakar, S. G., Jakop, M., Bavec, M., and Bavec, F. 2012. "Allelopathic Effects of Amaranthus retroflexus and Amaranthus cruentus Extracts on Germination of Garden Cress." African Journal of Agricultural Research 7 (10): 1492-7.

[15] Dogaru, G. V., Budoi, S. G., and Sandoiu, D. D. I. 2012. "Determination of the Amaranthus retroflexus Damage Threshold in Maize Crop." Advances in Agriculture and Botanic 4 (1): 1-5.

[16] Namdari, T., Amini, R. A., Sanayei, S., Alavi-Kia, S., and Mohammadi-Nasab, A. D. 2012. "Allelopathic Effects of Redroot Pigweed (Amaranthus retroflexus L.) Root Exudates on Common Bean Seedling Growth." International Research Journal of Applied and Basic Sciences 3 (6): 1230-4. 


\section{Allelopathic Effects of Different Organs of Redroot Pigweed (Amaranthus retroflexus L.) on Cucumber and Wheat Plants}

[17] Sarabi, V., Rashed-Mohassel, M. H., and Valizadeh, M. 2011. "Response of Redroot Pigweed (Amaranthus retroflexus L.) to Tank Mixtures of 2,4-D Plus MCPA with Foramsulfuron." Australian Journal of Crop Science 5 (5): 605-10.

[18] Bajalan, I., Zand, M., and Rezaee, S. 2014. "Allelopathic Effect of Various Organs of Walnut (Juglans regia) on Seed Germination of Wheat." Canadian Journal of Pure and Applied Sciences 8 (2): 2859-63.

[19] Enayatgholizadeh, M. R. 2014. "Effect of Different Organs Juices of Lactuca, Alfalfa and Rumex on Germination and Seedling Growth of Wheat." Indian Journal of Fundamental and Applied Life Sciences 4: 1027-35.

[20] Tomlinson, K. W., Sterck F. J., Bongers, F., Da Silva, D. A., Barbosa, E. R. M., Ward, D., Bakker, F. T., Van Kaauwen, M., Prins, H. H. T., De Bie, S., and Van Langevelde, F. 2012. "Biomass Partitioning and Root Morphology of Savanna Trees across a Water Gradient." Journal of Ecology 100 (5): 1113-21.

[21] Kusmana, C. 2010. "The Growth of Rhizophora mucronata and Avicennia marina Seedlings Planted Using Guludan Technique in Coastal Area of Jakarta." Presented at the 5th Kyoto University Southeast Asia Forum of the Earth and Space Sciences, Bandung Technolgy Institute, January 7-8, 2010, Bandung.

[22] Hernández, E. M., Corona-Rangel, M. L., Corona, A. E., Cantor del Angel, J. A., Sánchez-López, J. A., Sporer, F., Wink, M., and Bermúdez-Torres, K. 2011. "Quinolizidine Alkaloid Composition in Different Organs of Lupinus aschenbornii." Brazilian Journal of Pharmacognosy 21: 824-8.

[23] Narwal, S. S., and Tauro, P. 1996. "Allelopathy in Pests Management for Sustainble Agriculture." In Proceeding of the International Conference on Allelopathy, 23-65.

[24] Owen-Going, T. N., Beninger, C. W., Sutton, J. C., and Hall, J. C. 2008. "Accumulation of Phenolic Compounds in Plants and Nutrient Solution of Hydroponically Grown Peppers Inoculated with Pythium aphanidermatum." Canadian Journal of Plant Pathology 30 (2): 214-25.

[25] Mothes, K. 1955. "Physiology of Alkaloids: Annual Review." Plant Physiol. 6: 393-432. 